\title{
CORPO, MASCULINIDADE, ETNIA E MÚSICA
}

\author{
Lucidalva Correia Assunção \\ Universidade Estadual de Feira de Santana
}

RESUMO: Apresentar algumas questões introdutórias sobre a música popular brasileira, no período de 1920-1960. Destacar as décadas de 20-40 e, nessa incursão, evidenciar a representação do corpo do homem negro em três canções do período supracitado.

PALAVRAS-CHAVE: MPB; masculinidade; etnia.

\section{PRELIMINAR}

O período de 1920-1960 abre e fecha um ciclo de acontecimentos históricos no Brasil. A década de 20 registra o início do processo de industrialização e conseqüente utilização da música popular brasileira como produto vendável. A década de 60 é marcada pela mudança na fisionomia do cenário da música popular, com o surgimento da Bossa Nova.

O tema proposto é amplo, complexo, articulado e sugestivo. Interessante tanto do ponto de vista do estudo das expressões identitárias, quanto do itinerário da MPB e sua importância/influência na formação da identidade nacional brasileira.

A análise das três canções é básica, principalmente sobre o aspecto da masculinidade. Trata-se, antes, de uma apreciação desprovida de grandes intenções, resultado de leituras recentes na área em questão e das contribuições do Prof. Dr. Chistopfer Laferl, obtidas durante a realização de seminários na Universidade Federal de Bahia.

O corpus utilizado não é o bastante para chegarmos a conclusões "definitivas". O interessante seria trabalhar com um número mais significativo de canções, por década, especialmente 
as das décadas de 20-40. Ficamos devendo uma discussão mais produtiva.

A exemplo de todo e qualquer trabalho que se quer andarilho, estamos, ainda, aprofundando os temas e, mesmo com toda a vigilância possível, não escapamos de um discurso perigoso (Laferl, 2000) em se tratando da análise de produtos culturais; discurso este, a exemplo do aqui criticado, carregado de preconceitos e clichês.

\section{MPB (1920-1960): ALGUMAS CONSIDERAÇÕES}

A mistura deu samba - esta expressão foi retirada do livro de Wandenyr Caldas (1985). Então, perguntamos: de qual mistura se fala? E como se processou esta mistura? Para Caldas, trata-se de uma mistura eqüitativa: isto mais aquilo se misturam para formar aquilo outro. Ou seja, da mistura da polca, da habanera, do lundu, do batuque com um toque especial de brasilidade, no modo de executar as canções, apareceu o samba.

Dito assim, parece-nos algo bastante homogêneo, sem problematização. Esta idéia lembra-nos aquela velha história da mistura das raças como dádiva dos deuses. Analogamente, a mistura dos ritmos europeus com os africanos, como produto de uma fecundação e gestação harmoniosas.

Como é do conhecimento nosso, no período da escravidão legalizada e depois dele, após a "abolição", até a consagração do samba como ritmo de prestígio nacional, as manifestações culturais do negro foram reprimidas violentamente pelas elites dominantes.

Estas manifestações serviram, como bem diz Sodré (1998), de resistência ao imperativo social e por conta da constante violação ao direito de livre manifestação, o negro, para manter viva as suas tradições e resistir à pretensa ordem estabelecida pelos brancos, se viu "obrigado" a incorporar elementos da tradição européia em sua cultura. Por isso, vemos na produção negrobrasileira esta mistura de que nos fala Caldas. É óbvio que em se tratando de contatos sócio-culturais as trocas são quase inevitáveis. Mas, se lembrarmos do processo de fragmentação do latim e conseqüente formação das línguas românicas, guardadas as devidas proporções, saberemos analisar a questão acima de forma menos adocicada. 
Após a "abolição", os negros nordestinos, especialmente os baianos, migraram para o Rio de Janeiro, na época, sede da Corte e posteriormente da Republica Federativa do Brasil. O Rio de Janeiro transformou-se em um foco aglutinador dos bambas da perna veloz e do corpo sutil (SODRÉ, 1998). Um centro de convergência das massas, especialmente concentradas no bairro da Saúde, na zona da Cidade Nova (Praça Onze) e na Gamboa.

O corpo do negro, antes reprimido, no decurso dos anos 20 adquire outras dimensões. Este novo corpo passa a ser apreciado como exótico, erótico e pitoresco, ajustando-se ao gosto de um público pronto a consumi-lo.

As composições oriundas das Praças, das casas das Tias deixaram de ter apenas valor de uso e passam a ter valor de troca. Modifica-se a forma de compor (antes gratuita), modificam-se também as relações sociais entre o próprio grupo pertencente às camadas mais pobres da sociedade.

Recapitulando: a década de 20 apresenta mudanças no quadro da produção artística negro-brasileira. De um lado, a divulgação e a profissionalização do samba, de outro lado, a expropriação desse bem em prol das classes privilegiadas.

As décadas de 30 e 40 serão marcadas por uma fase também de apropriação desse bem, até mesmo pelo governo varguista, através de sua política de boa-vizinhança com os Estados Unidos. A consagração de compositores, de intérpretes e de conjuntos regionais se deu por conta da introdução de uma música ao gosto da classe média emergente. Ao gosto do freguês.

\section{REPRESENTAÇÃO DO CORPO DO HOMEM NEGRO NA MÚSICA POPULAR BRASILEIRA}

Não há como falar de samba, de lundu ou de outros gêneros musicais provenientes do século passado, deixando de lado a questão da etnicidade, do gênero e da representação do corpo no imaginário dos compositores, intérpretes, dançarinos e músicos. Por quê? Por que estes ritmos foram e são os mais utilizadas pelo povo negro escravizado ou liberto, pertencentes às classes marginalizadas do país. O mesmo corpo que antes se revelava no canto-dança em forma de ritual, hoje é tomado apenas como corpo funcional. 
O interessante, segundo Denise Sant'Anna (1997), é "não ficar apenas na história do corpo, mas problematizar esta história e refletir aquilo que chamamos de dados naturais, não buscar o corpo, mas as práticas sociais, as marcas discursivas presentes na manifestação desse corpo".

A perspectiva apontada por Sant'Anna possibilita um estudo das canções a partir das marcas discursivas presentes na manifestação do corpo negro do homem e da mulher na MPB. Essa é uma tarefa árdua, de que os estudos existentes ainda não dão conta, e no momento, não estamos em condição de cumpri-la.

Ao observarmos as letras das canções do período em destaque, décadas de 20-60, perceberemos, de imediato, a utilização do corpo (em grande escala do corpo feminino negro/mulato/moren) dentro de uma visão funcional - o corpo a serviço de algo.

A questão da masculinidade, isto é, o estudo do homem enquanto gênero nas malhas do discurso musical, a nosso ver, é um dado recente e no caso específico da MPB não pode está dissociado de uma outra questão, tão importante quanto esta: a análise das relações entre as classes e do processo de colonização e escravidão pelo qual passamos.

$O$ que se tem de verdade sobre a representação do corpo masculino e feminino na MPB não passa de constructos sociais ratificados ou retificados em cada época e lugar. Sem o estudo integrado das relações de poder entre as classes, entre as raças e entre os gêneros não dá para entender, por exemplo, como o samba, no Brasil, e o son, em Cuba, se mostram tão representativos, transformando-se em registros de identidade nacional brasileira e cubana, respectivamente.

Agora, faremos uma rápida leitura das canções: Terra seca, de Ary Barroso; O negô no samba, de Ary Barroso e Luiz Peixoto; Meu mulato, de João de Barro e Júlio Casado.

\section{TERRA SECA}

O $e u$ da canção não se identifica claramente enquanto gênero e etnia. Mas, rastreando as marcas lingüísticas da canção, podemos arriscar duas hipótese não opostas: 
a) $\mathrm{O} e u$ é um homem negro, falando indiretamente com um $t u$ (o sinhô) sobre sua condição de escravo. Trata-se de um discurso produzido em terceira pessoa. Entretanto, a presença da primeira pessoa, em lugar da terceira, comprovável nos versos 7-8, 22-23 "Ai, meu sinhô / Negô tá veio, não agüenta"; "Negô era moço I E a vida um brinquedo pra mim", quebra a harmonia da estrutura discursiva, denunciando, assim, uma possível relação $e u-t u$, ao invés de ele-tu. Some-se a essa constatação a fala de uso popular utilizada pelo emissor da mensagem, característica das camadas sociais marginalizadas. Esta hipótese aponta-nos para o processo de nulificação do sujeito $(e u)$, através do uso da terceira pessoa, eufemicamente acentuado, para indicar a inferioridade de quem fala.

b) Benveniste (1995) afirma que: “... a 'terceira pessoa' não é uma 'pessoa', é inclusive a forma verbal que tem por função exprimir a 'não-pessoa'. E, ainda; o sujeito está expresso na relação $e u-t u$. Somente o sujeito pode manifestar. O discurso formulado em terceira pessoa não identifica quem ou $o$ que. Estamos, pois, diante de um "sujeito" universal, ou, diante de um caso típico de multiplicação do "sujeito" ou, ainda, ausência de "sujeito". Retornamos, aqui, à hipótese $a$. Acontece que, com o processo de universalização ou multiplicação do "sujeito", o falante, enquanto pessoa, se apaga. Esse fato pode nos indicar, também, a inferioridade do ele em relação à pessoa com quem se fala.

Podemos, a partir daí, inferir que tanto numa proposição (nulificação do sujeito), quanto noutra (multiplicação do sujeito), o racismo vem embutido nas teias discursivas. Trata-se de um protesto conformado, que apresenta um acontecimento social, cultural e econômico de forma naturalizada, sem uma definição precisa das personagens, do cenário (lugar) e das relações de poder.

Sem sombra de dúvida, temos um exemplo da visão funcional do corpo do homem negro-escravo, cuja função reside, unicamente, em trabalhar até a morte, sem a devida recompensa. "Trabaiá, trabaiá nêgo" (vs. 2, 3, 5, 6, 11, 12, 14,15).

O corpo do negro carrega o peso do cansaço de uma vida inteira dedicada à servidão. A terra se modifica, a criança tornase adulta, mas o corpo do homem negro-escravo permanece continuamente como fonte produtiva de riqueza para o branco.

O título Terra seca serve-nos tanto para caracterizar a terra 
propriamente dita, local de plantio esgotado pelo uso, quanto para caracterizar o corpo do homem negro-escravo, sem vida, semelhante à terra que se explora à exaustão.

\section{O NÊGO NO SAMBA}

Prevalece, ainda, a visão instrumental de corpo, dentro de uma outra perspectiva. Agora, o corpo proporcionará alegria, bem estar e prazer. Esta mudança de papel (de local de servidão) tem uma estreita relação com a própria história brasileira. Anteriormente, o corpo do negro, como já dissemos, foi negado em se tratando de expressões culturais, hoje, a sua apropriação e expropriação se dão mediante ao uso de estratégias diferentes, adaptadas às exigências locais. Este corpo continua a produzir riqueza no desempenho de novas tarefas.

A canção $O$ nêgo no samba traz a fala de uma mulher que não se identifica claramente enquanto etnia. Pressupomos, consoantes aos códigos culturais da época, ser esta a fala de uma mulher negra e pobre, sobre um homem negro e pobre.

"Samba de nêgo, meu bem / Me deixa tonta" (vs. 7-8), o $e u$ da canção exalta as qualidades do samba de negro. No cumprimento desse propósito, estabelece um jogo opositivo entre: o samba sambado pelo branco e o samba sambado pelo negro, reforçando, assim, o mito do inatismo "Num samba, branco não tem jeito meu bem / Num samba, nêgo nasce feito" (vs. 11-12). Este mito é bastante cultivado atualmente, tomemos como exemplo, o vocalista do grupo Harmonia do Samba, o Xandy.

O negro é focalizado através de seu corpo e da função erótica e exótica nele representadas. Partindo dessa direção, tanto o corpo da mulher negra/mulata/morena, quanto do homem negro/ mulato assumem características similares.

\section{MEU MULATO}

Nesta canção, o apelo sexual, embora transubstanciado pelo auxílio das metáforas, ganha contornos bem definidos. Trata-se de uma declaração de amor feita por uma mulher negra (eu) a um 
mulato (ele).

Esta declaração, todavia, é indiretamente pronunciada, já que, semelhante à canção anterior, o discurso lingüístico se realiza de forma triangular: um eu que fala para um tu sobre um ele (mulato/ negro).

O apelo sexual aparece na terceira estrofe da canção, em versos metaforizados que escondem nos véus das palavras e no uso das reticências as peripécias de uma noite de amor: a narrativa da êxtase do prazer banhada pela noite enluarada.

Novamente, uma oposição entre branco e negro a favor deste. O negro naturalmente é apresentado como aquele que traz o samba no pé, que na vida é igual a um cabo, no samba a um general e no amor "Vale mais que coroné" (v. 8), faz o pinho da cama gemer. "E o corpo todo dessa nêga treme / Quando de noite de clarão de lua / O pinho geme, o cavaquinho chora /(...) lá na minha rua".

\section{CONCLUSÕES}

Neste espaço, recuperaremos idéias fundamentais, em forma de síntese, das questões apresentadas. Apesar das inevitáveis lacunas aqui contidas, podemos arriscar algumas conclusões, óbvias, pois:

Os clichês utilizados nas cações para definir a mulata/ negra/morena são os mesmos para o homem mulato/negro no campo da dança e do jogo de sedução. O olhar lançado a ambos recorta apenas algumas partes específicas de seu corpo (os quadris) e os prazeres (efeitos) dele obtidos por meio de seu movimento sestroso, bamba e "inato";

- O homem mulato/negro não é dotado de voz própria, não aparece como sujeito, falando de si mesmo;

- Das três canções, duas apresentam um $e u$ feminino que fala sobre as características do homem mulato/negro: sua condição de sambista e macho (as duas coisas estão imbricadas). Esta predileção pela voz feminina em detrimento da masculina se justifica pelo sistema de coordenadas da época e local em foco. Causaria estranheza se o elogio dirigido a um homem partisse de um outro homem. 
RÉSUMÉ: Présenter quelques questions introductives sur la musique populaire brésilienne, pendant la période 1920-1960. Mettre en relief les décennies 20-40 et, ce faisant, rendre saillant la représentation du corps de l'homme noir à travers trois chansons de la période citée ci-dessus.

MOTS CLËS: MPB; masculinité; ethnie.

\section{REFERÊNCIASBILBIOGRÁFICAS}

BADINTER, Elisabetb. $X Y$ sobre a identidade masculina. Tradução de Maria Ignez Duque Estrada. 2. ed. Rio de Janeiro: Nova Fronteira, 1993. 266p.

BARBOSA, Maria José Solemarte. Chorar, verbo transitivo.In. CADERNOS PAGU (11). São Paulo, Campinas: IFCH/UNICAMP, 1998:321-342. BENVENISTE, Émile. Problemas de lingüística geral I. Trad. de Maria da glória Novak e Maria Luisa Neri. 4. ed. Campinas, SP: Pontes, 1995: 247-59: 272-83.

CALDAS, Waldenyr. Samba: nasce o remelexo brasileiro. In. id. Iniciação à música popular brasileira. São Paulo: Ática, 1985:28-45.

MUNAGA, Kabengele. As facetas de um racismo silenciado. In. SCHWARCZ, Lilia M. e QUEIROZ, Renato da Silva (Org.). Raça e diversidade. Edusp, sd. p. 213-229.

SANT'ANNA, Denise Bernuzzi de. O corpo entre antigas referências e novos desafios. In: Cadernos de Subjetividade. São Paulo, 5 (2), dezembro/1997:275-284.

SODRÉ, Muniz. Samba, o dono do corpo. 2. ed. Rio de Janeiro: Mauad, 1998, 112p.

TINHORÃO, José Ramos. Música popular: um tema em debate. 3. ed. rev. e ampliada. São Paulo: Ed. 34, 1998. 365 p. 